\title{
Factors influencing parental decision about genetics evaluation for their deaf or hard-of-hearing child
}

\author{
Christina G. S. Palmer, PhD ${ }^{1,2}$, Jason T. Lueddeke, BA ${ }^{1}$, and Jin Zhou, MS ${ }^{3}$
}

\begin{abstract}
Purpose: To identify factors that are associated with why parents of deaf children who have had GJB2/GJB6 testing as part of a genetics research study do or do not take their children for genetics evaluation. Methods: Self-administered questionnaire was completed by parents of a deaf child participating in a $G J B 2 / G J B 6$ testing study. Results: A total of 30 parents (representing 24 children) completed the questionnaire; 11 of 24 children (46\%) underwent a genetics evaluation. Compared with parents who did not take their child for a genetics evaluation, those who did were more likely to (1) have supportive pediatricians, (2) feel it was important or would be helpful to their child, (3) recall the recommendation for evaluation, (4) have family members who wanted the child to have an evaluation, and (5) be Hispanic or Asian. Genetic test results, knowledge of genetics evaluation, psychosocial factors, language concerns, or structural factors were not substantively associated with attending a genetics evaluation. Conclusion: Parental perceptions, family environment, and pediatricians play a role in decisions regarding genetics evaluation. Because genetic testing for deafness likely will occur outside of traditional genetics clinics and without comprehensive genetics evaluation, efforts to increase pediatricians' awareness of the usefulness of genetics evaluation may be essential to ensure appropriate care for deaf and hard-of-hearing children as recommended by the American College of Medical Genetics. Genet Med 2009:11(4):248-255.
\end{abstract}

Key Words: deafness, hearing loss, genetic test, GJB2, connexin 26, cx26, newborn hearing screening

C ongenital deafness is relatively common, present in 1-3 of 1000 newborns. ${ }^{1,2}$ Although etiologically heterogeneous, at least $50 \%$ of early onset deafness is genetic, and among genetic cases, most are likely to be autosomal recessive, and nonsyndromic., ${ }^{2,3}$ Because of the etiological heterogeneity of deafness, genetics evaluation and genetic counseling for deafness can be challenging, especially in young children. ${ }^{4}$ However, with recent identification of deafness-causing variants in the GJB2 and GJB6 genes, ${ }^{5-8}$ which have been found to account for up to $50 \%$ of autosomal recessive nonsyndromic deafness in some populations, ${ }^{9-11}$ genetics evaluation and genetic counseling have the potential to offer a great deal more to families compared with the past.

Shortly after GJB2 was identified, the Joint Committee on Infant Hearing $(\mathrm{JCIH})$ endorsed universal newborn hearing screening and initiation of intervention for deaf infants by 6 months of age ${ }^{12}$ because early detection and intervention could

From the Departments of ${ }^{1}$ Psychiatry and Biobehavioral Sciences, ${ }^{2}$ Human Genetics, and ${ }^{3}$ Biomathematics, University of California, Los Angeles, California.

Christina G. S. Palmer, PhD, UCLA Semel Institute, 760 Westwood Plaza, Room 47-422, Los Angeles, CA 90024. E-mail: cpalmer@mednet.ucla.edu.

Disclosure: The authors declare no conflict of interest.

Submitted for publication July 29, 2008.

Accepted for publication November 10, 2008.

DOI: 10.1097/GIM.0b013e318195aad9 offer infants the best opportunity to develop nearly age appropriate language. ${ }^{13}$ About the same time, the American College of Medical Genetics (ACMG) published a recommendation that all children with confirmed hearing loss be referred for genetics evaluation and counseling, ${ }^{14}$ a statement echoed by the JCIH. ${ }^{15,16}$ Newborn hearing screening has since become widely available in the United States and other countries ${ }^{17-19}$; however, widespread involvement of genetics service providers within the early hearing detection and intervention programs is lagging. ${ }^{20,21}$

The workup for a deaf infant can include a number of medical tests to establish the etiology of the deafness. ${ }^{22}$ However, in the absence of syndromic findings, GJB2 testing currently is recommended as the first test, ${ }^{14}$ followed by GJB6 deletion testing for negative or heterozygous $G J B 2$ results, ${ }^{23}$ and there is evidence that this genetic testing has become an important tool for nongenetics health providers, such as pediatric otolaryngologists, 22 to explain why infants identified through the newborn hearing screening process are deaf or hard of hearing. A potential benefit of $G J B 2 / G J B 6$ testing is that in some cases, it will explain why a child is deaf and eliminate the need for additional medical evaluation. ${ }^{24}$ A GJB2/GJB6 result that explains why a child is deaf will also provide mode of inheritance, recurrence chance, and psychological benefit to the parents. ${ }^{24,25}$ However, for a considerable number of cases, GJB2/GJB6 genetic testing will not explain why a child is deaf. Because inconclusive and negative genetic test results are difficult to explain and understand, ${ }^{26}$ and because the etiology of the child's deafness is still unknown, additional genetic and medical evaluation may be warranted. Although there are considerable benefits to GJB2/ GJB6 (and other DNA based) testing, recent empirical data suggest that nongenetics providers, such as pediatric otolaryngologists, do not have an adequate understanding of genetic testing and counseling of test results..$^{22} \mathrm{~A}$ significant issue that may surface in relation to $G J B 2 / G J B 6$ testing by nongenetics health providers is the importance of referral for genetics evaluation and genetic counseling for both positive and negative/ inconclusive results, particularly in light of a recent report that both deaf and hearing consumers would prefer to discuss genetic information with a professional trained in genetics such as a geneticist or genetic counselor. ${ }^{25}$

Despite recommendations by the ACMG and the JCIH regarding genetics evaluation and counseling, ${ }^{14-16}$ empirical experience suggests that perhaps only $\sim 50 \%$ of deaf or hard-ofhearing children are referred for genetics evaluation. ${ }^{27}$ Although referral is an important step in the process, parents are the final decision makers about whether or not to pursue genetics evaluation for their child, and there is evidence to suggest that some parents do not pursue an evaluation..$^{27}$ To date, there have been no published studies to examine why some parents of a deaf or hard-of-hearing child take their child for a genetics evaluation and others do not. Moreover, there have been no studies that specifically examine why parents of deaf children who have had GJB2/GJB6 testing outside of a genetics clinic choose or choose not to have their child undergo a genetics evaluation after receiving their results. 
There are a variety of factors that may explain variation in seeking health care which could apply to parental decisions to seek a genetics evaluation for their deaf or hard-of-hearing child. For instance, financial or structural obstacles can exist, ${ }^{28}$ such as inadequate transportation to a genetics clinic, locality of the clinic itself, or lack of health insurance or coverage for a genetics evaluation. In addition, cultural hindrances may be present, such as an individual's inability to speak the majority language (e.g., English in the United States) or communicate comfortably with a physician. ${ }^{29}$ Many individuals avoid information that may discomfort them, ${ }^{30}$ and because learning genetic information can be disturbing and uncomfortable for some people, ${ }^{31,32}$ they may view a genetics evaluation as a psychologically harmful process. Some people may fear being told their child's deafness is genetic ${ }^{33}$ whereas some may simply fear the unknown and do not wish to learn about what they do not understand. ${ }^{30}$ Others, however, may feel comfortable with their current understanding of why their child is deaf or hard of hearing, or believe that discovering the cause of their child's deafness is an irrelevant piece of information.

However, despite the potential barriers to seeking a genetics evaluation, there are parents who choose to learn more about why their child is deaf, and the explanation for this variability is currently unknown. By studying families of deaf and hard-of-hearing children identified through newborn hearing screening who are known to have received written and verbal recommendations for a genetics evaluation, we may be able to identify the factors that influence parents' decisions regarding the evaluation that extend beyond simple lack of awareness. Furthermore, by studying families who underwent GJB2/GJB6 testing and counseling outside of a traditional genetics clinic, we may better understand the factors involved in parental decisions about genetics evaluation as these factors apply to this context. The purpose of this study is to identify factors that explain why parents of deaf or hard-of-hearing children who have had GJB2/GJB6 testing outside of a genetics clinic do or do not take their children for genetics evaluation, with the ultimate goal of minimizing these sources of variation to optimize health care for these children.

\section{MATERIALS AND METHODS}

\section{Sample}

The sample is composed of parents who participated in the University of California, Los Angeles (UCLA) Genetics of Hearing Loss (GHL) study. The purpose of the GHL study was to examine clinical, educational, and psychosocial outcomes of GJB2/GJB6 testing in deaf or hard-of-hearing children under the age of 3 years. Participants in the GHL included deaf infants/toddlers and their parents, who were recruited through a variety of venues in the Los Angeles area, including UCLA newborn nursery, genetics, audiology, and otolaryngology clinics, and education intervention programs. Parents could enroll in the GHL study at two different time points: after referral through newborn hearing screening (before confirmed audiologic diagnosis) or after identification of the child as deaf/hard of hearing. As part of the GHL study, a board-certified genetic counselor provided information about genetics of deafness and GJB2/GJB6 testing to parents. With parental informed consent, $G J B 2 / G J B 6$ testing was performed on the child, and the genetic counselor explained the test results to parents in a face-to-face counseling session. Additional details of the GHL study methodology can be found in Refs. 34-36. Regardless of the genetic test results, the genetic counselor recommended a genetics evaluation for the child and all parents received written information about local genetics clinics, and copies of the ACMG and American Academy of Pediatrics (a member of JCIH) guidelines for care of a deaf or hard-of-hearing child. The exception to this recommendation occurred for four families (six parents) enrolled at prediagnosis whose child subsequently passed outpatient hearing screening. Information regarding follow-up on the genetics evaluation recommendation was not systematically collected as part of the GHL. A total of 164 parents from 103 families were enrolled in the GHL study. The current study focuses on the 99 families (158 parents) who received a recommendation for genetics evaluation for their child. Of these 99 families, 94 (151 parents) gave permission to be recontacted for future studies and were eligible to participate in the current study.

\section{Procedures}

Between April and November 2007, 151 eligible parents representing 94 families were mailed a letter of invitation to participate in this study with up to three mailings to increase sample size. The study questionnaire was subsequently mailed to parents who consented to participate. This study was approved by the UCLA institutional review board.

\section{Questionnaire construction}

A self-administered mailed questionnaire was developed to identify factors associated with parental decisions about a genetics evaluation. Eight potential factors were selected for investigation from pertinent literature in genetic counseling, health services research, and health psychology (Table 1). These factors encompassed structural aspects (health insurance possession and coverage; general location and proximity of a genetics clinic; and transportation availability), potential concerns about language barriers, perceived importance of a genetics evaluation, psychosocial issues in relation to feelings of discomfort that might arise in a genetics evaluation, knowledge and understanding of genetics evaluations, family's role, pediatrician's role (parental request for a genetics referral; pediatrician's provision of a referral; pediatrician's knowledge of deafness; and pediatrician's interest in a genetics evaluation), and role of GJB2/GJB6 counseling session. Basic demographic information and genetic test results were previously collected through the GHL and available for use in the study.

The questionnaire contained 36 multiple option items (primarily yes/no/unsure and Likert scale response categories) and an openended item that asked parents to briefly describe why their child has $\mathrm{had} / \mathrm{has}$ not had a genetics evaluation. The questionnaire was pilot tested for clarity, revised, and translated into Spanish using a translation-back translation procedure ${ }^{37}$ to ensure maximum equivalence between the English and Spanish versions.

\section{Analysis plan}

To examine the representativeness of the current sample to the larger GHL sample, the two samples were compared on a variety of demographic, audiologic, and genetic indices using Fisher's exact test and $t$-test for qualitative and quantitative variables, respectively. Parents in the current sample were then divided into two groups: those who reported taking their child for a genetics evaluation after they learned their child's GJB2/ GJB6 test results and those who reported that they did not take their child for a genetics evaluation. Fisher's exact test and $t$-test were performed to identify qualitative and quantitative factors, respectively, that were associated with whether or not parents took their child for a genetics evaluation. Because this sample contains six instances where both members of the couple com- 
Table 1 Survey items and results of analyses to identify factors associated with whether or not parents took their child to a genetics evaluation

Question

Took child for genetics evaluation ( $n=12$ parents; 11 families)
Did not take child for genetics evaluation $(n=18$ parents; 13 families)

Structural variables

Do you have a reliable method of transportation to take your child to see a genetics doctor?

Are there genetics doctors in your city?

Can you get to a genetics doctor easily?

Does your child have health insurance?

Does your child's health insurance cover a visit to a genetics doctor?

Potential language barriers

I was (am) worried that I would (will) receive information in a language I am not comfortable with.

I was (am) worried that the doctor would (will) communicate with me only in English.

Perceived importance of genetics evaluation

In your opinion, how important is (was) it for your child to be examined by a genetics doctor.

Psychosocial variables

I was (am) worried that I would (will) learn information that will make me feel uncomfortable.

I was (am) worried that I would (will) be told that I should not have any more children.

I was (am) worried that a genetics evaluation would (will) not make me feel better.

I was (am) worried that I would (will) find out that I caused my child's hearing loss.

I was (am) worried about learning more about my child's hearing loss.

I was (am) comfortable with what I already know about my child's hearing loss.

I was (am) worried that I would (will) not understand what the doctor tells me.

Knowledge and understanding

Do you know why your child has hearing loss?

I understand what happens during a genetics evaluation.

During a genetics evaluation of a child with hearing loss .. .

The child has a physical exam

The family history is discussed

The doctor tries to identify the cause of the hearing loss in the child

Recommendations for other tests are made

The chance of having another child with hearing loss is discussed
Yes: $100 \%$

Yes: $67 \%$, no: $8 \%$, unsure: $25 \%$

Yes: $83 \%$, no: $17 \%$

Yes: $92 \%$, no: $8 \%$

Yes: $75 \%$, no: $0 \%$, unsure: $25 \%$

$\mathrm{SA} / \mathrm{A}=8.3 \%, \mathrm{~N}=8.3 \%$,

$$
\mathrm{SD} / \mathrm{D}=83.3 \%
$$

$\mathrm{SA} / \mathrm{A}=18.2 \%, \mathrm{~N}=9.1 \%$ $\mathrm{SD} / \mathrm{D}=72.7 \%$

Very $=83.3 \%$, somewhat $=16.7 \%$, not important $=0 \%$

$$
\begin{aligned}
& \mathrm{SA} / \mathrm{A}=50 \%, \mathrm{~N}=8.3 \%, \\
& \mathrm{SD} / \mathrm{D}=41.7 \% \\
& \mathrm{SA} / \mathrm{A}=25 \%, \mathrm{~N}=8.3 \%, \\
& \mathrm{SD} / \mathrm{D}=66.7 \% \\
& \mathrm{SA} / \mathrm{A}=25 \%, \mathrm{~N}=33.3 \%, \\
& \mathrm{SD} / \mathrm{D}=41.7 \% \\
& \mathrm{SA} / \mathrm{A}=8.3 \%, \mathrm{~N}=16.7 \%, \\
& \mathrm{SD} / \mathrm{D}=75 \% \\
& \mathrm{SA} / \mathrm{A}=25 \%, \mathrm{~N}=0 \%, \\
& \mathrm{SD} / \mathrm{D}=75 \% \\
& \mathrm{SA} / \mathrm{A}=50 \%, \mathrm{~N}=16.7 \%, \\
& \mathrm{SD} / \mathrm{D}=33.3 \% \\
& \mathrm{SA} / \mathrm{A}=16.7 \%, \mathrm{~N}=0 \%, \\
& \mathrm{SD} / \mathrm{D}=83.3 \%
\end{aligned}
$$

Yes: $33.3 \%$

$\mathrm{SA} / \mathrm{A}=83.3 \%, \mathrm{~N}=8.3 \%$, $\mathrm{SD} / \mathrm{D}=8.3 \%$

True: $66.7 \%$

True: $100 \%$

True: $91.7 \%$

True: $58.3 \%$

True: $83.3 \%$
Yes: $100 \%$

Yes: 61\%, no: 6\%, unsure: 33\%

1.0

Yes: $89 \%$, no: $11 \%$

1.0

Yes: $100 \%$, no: $0 \%$

0.40

Yes: $39 \%$, no: $6 \%$, unsure: $56 \%$

$\mathrm{SA} / \mathrm{A}=11.1 \%, \mathrm{~N}=5.6 \% \mathrm{SD} / \mathrm{D}=$

$83.3 \%$

$\mathrm{SA} / \mathrm{A}=11.1 \%, \mathrm{~N}=5.6 \% \mathrm{SD} / \mathrm{D}=$ $83.3 \%$

Very $=11.8 \%$, somewhat $=23.5 \%$, $<0.0001$ not important $=64.7 \%$

$\mathrm{SA} / \mathrm{A}=5.6 \%, \mathrm{~N}=11.1 \%, \mathrm{SD} / \mathrm{D}$ $=83.3 \%$

$\mathrm{SA} / \mathrm{A}=11.1 \%, \mathrm{~N}=16.7 \%, \mathrm{SD} / \mathrm{D}$ $=72.2 \%$

$\mathrm{SA} / \mathrm{A}=11.1 \%, \mathrm{~N}=0 \%, \mathrm{SD} / \mathrm{D}=$ $88.9 \%$

$\mathrm{SA} / \mathrm{A}=22.2 \%, \mathrm{~N}=0 \%, \mathrm{SD} / \mathrm{D}=$ $77.8 \%$

$\mathrm{SA} / \mathrm{A}=5.6 \%, \mathrm{~N}=16.7 \%, \mathrm{SD} / \mathrm{D}$ $=77.8 \%$

$\mathrm{SA} / \mathrm{A}=66.7 \%, \mathrm{~N}=11.1 \%, \mathrm{SD} / \mathrm{D}$ $=22.2 \%$

$\mathrm{SA} / \mathrm{A}=16.7 \%, \mathrm{~N}=11.1 \%, \mathrm{SD} / \mathrm{D}$ $=72.2 \%$

Yes: $33.3 \%$

$\mathrm{SA} / \mathrm{A}=55.6 \%, \mathrm{~N}=27.8 \%, \mathrm{SD} / \mathrm{D}$

$$
=16.7 \%
$$

True: $58.8 \%$

0.72

True: $100 \%$

True: $94.4 \%$

True: $100 \%$

0.007

True: $100 \%$ 
Table 1 Continued

Did not take child for genetics

evaluation ( $n=18$ parents; 13 families)

$P$

Question

( $n=12$ parents; 11 families $)$

$$
\begin{gathered}
\mathrm{SA} / \mathrm{A}=41.7 \%, \mathrm{~N}=25 \%, \\
\mathrm{SD} / \mathrm{D}=33.3 \%
\end{gathered}
$$

Very $=33.3 \%$, somewhat $=41.7 \%$, not knowledgeable $=25 \%$

Very $=41.7 \%$, somewhat $=33.3 \%$, not interested $=25 \%$

Yes: $36.4 \%$, no: $63.6 \%$

Yes: $36.4 \%$, no: $63.6 \%$

Did your child's pediatrician give you a referral to see a genetics doctor ${ }^{a}$

Role of GJB2/GJB6 counseling session

The counseling session made me feel like . . .

I learned everything I needed to know about why my child has hearing loss.

A visit to a genetics doctor could help my child.

A visit to a genetics doctor would give me more information about my child's hearing loss.

The genetic counselor helped me understand what happens during a genetics evaluation with a genetics doctor.

The genetic counselor recommended that my child go to see a genetics doctor.

Demographic variables

Ethnicity/race-parents

$$
\begin{aligned}
& \mathrm{SA} / \mathrm{A}=16.7 \%, \mathrm{~N}=8.3 \%, \\
& \mathrm{SD} / \mathrm{D}=75 \% \\
& \mathrm{SA} / \mathrm{A}=41.7 \%, \mathrm{~N}=50 \%, \\
& \mathrm{SD} / \mathrm{D}=8.3 \% \\
& \mathrm{SA} / \mathrm{A}=58.3 \%, \mathrm{~N}=33.3 \%, \\
& \mathrm{SD} / \mathrm{D}=8.3 \% \\
& \mathrm{SA} / \mathrm{A}=90.9 \%, \mathrm{~N}=9.1 \%, \\
& \mathrm{SD} / \mathrm{D}=0 \%
\end{aligned}
$$

Yes: $67 \%$, no: $8 \%$, unsure: $25 \%$

$$
\begin{aligned}
& \mathrm{SA} / \mathrm{A}=11.1 \%, \mathrm{~N}=27.8 \%, \mathrm{SD} / \mathrm{D} \\
& \quad=61.1 \%
\end{aligned}
$$

Very $=22.2 \%$, somewhat $=61.1 \%$,

not knowledgeable $=16.7 \%$

Very $=0 \%$, somewhat $=25 \%$, not interested $=75 \%$

Yes: $0 \%$, no: $100 \%$

Yes: $0 \%$, no: $100 \%$

$$
\begin{aligned}
& \mathrm{SA} / \mathrm{A}=44.5 \%, \mathrm{~N}=11.1 \%, \mathrm{SD} / \mathrm{D} \\
& \quad=44.4 \% \\
& \mathrm{SA} / \mathrm{A}=16.7 \%, \mathrm{~N}=38.9 \%, \mathrm{SD} / \mathrm{D} \\
& \quad=44.4 \% \\
& \mathrm{SA} / \mathrm{A}=38.9 \%, \mathrm{~N}=44.4 \%, \mathrm{SD} / \mathrm{D} \\
& \quad=16.7 \% \\
& \mathrm{SA} / \mathrm{A}=66.7 \%, \mathrm{~N}=11.1 \%, \mathrm{SD} / \mathrm{D} \\
& \quad=22.2 \%
\end{aligned}
$$

Yes: 28\%, no: 44\%, unsure: $28 \%$

\section{White}

$25 \%$

$41.7 \%$

$66.7 \%$

Hispanic

Asian

Median education level_-parents

Age at current study-parents (SD)

34.9 yr (5.7)

$\%$ deaf/hard of hearing_-parents

$3.1 \mathrm{yr}(1.3)$

$$
27.8 \%
$$$$
5.6 \%
$$$$
>\$ 80
$$

4 yr of college

37.2 yr (4.3)

$3.3 \mathrm{yr}(0.9)$

$30.8 \%$

$\%$ Children with GJB2/GJB6-related deafness ${ }^{a}$

$18.2 \%$

SA, strongly agree; A, agree; $\mathrm{N}$, neutral; $\mathrm{D}$, disagree; SD, strongly disagree.

${ }^{a}$ Analyses based on 24 independent families.

pleted a questionnaire, we randomly excluded one member of each couple and conducted preliminary analyses with and without the excluded respondents. Results did not substantively differ, indicating that the responses from the total sample can be treated as independent. Hence, we report the results of analyses from all 30 respondents, except for a subset of variables which can only be counted once per family (whether or not asked pediatrician for referral, whether or not pediatrician gave referral, family income, GJB2/GJB6 status of child, child's age) where we report results of analyses on the 24 families. Likert scale items were analyzed as quantitative variables for greater power; however, for ease of interpretation, we present the distribution of responses rather than the means. Alpha of 0.05 was used to determine statistical significance. 


\section{RESULTS}

\section{Sample characteristics}

Of the 151 eligible parents, 28 were unreachable because of address change or unknown address. Of the remaining 123, 30 parents representing 24 families completed the questionnaire for a response rate of $24.3 \%$. Table 2 provides sample demographic information for the current study and compares it with the 158 parents who received a recommendation to take their child for a genetics evaluation in the larger GHL study. As shown in Table 2, the current study sample does not significantly differ from the larger GHL study on any of these demographic factors, suggesting that the study sample is representative of the larger sample on a variety of demographic, audiologic, and genetic indices. In 11 of the 24 families, the deaf child underwent a genetics evaluation $(45.8 \%)$, for a total of 12 parents $(40 \%)$ who took their child for a genetics evaluation and 18 parents who did not.

As shown in Table 1, parents who took their child for a genetics evaluation rated the importance of the evaluation as higher than the other parents $(P<0.0001)$, and were more likely to feel that their family wanted their child to have a genetics evaluation $(P=0.04)$. The feeling that such an evaluation would help their child approached statistical significance $(P=0.056)$. Most parents felt that their pediatricians were "somewhat or very knowledgeable" about their child's deafness; however, those who took their child to a genetics evaluation rated their pediatrician's interest in a genetics evaluation as higher than did the other parents $(P=0.003)$, and those families were more likely to ask for $(36.4 \%$ vs. $0 \%, P=0.03)$ and receive a referral $(36.4 \%$ vs. $0 \%, P=0.03)$ from their pediatrician. These parents also were more likely to recall the recommendation for the evaluation $(67 \%$ vs. $28 \%, P=0.05)$. Parents did not differ substantially in their reported knowledge and understanding of a genetics evaluation; however, parents who took their child to genetics evaluation were less likely to respond that recommendations for other tests are made during an evaluation compared with the other parents $(P=0.007)$. This result suggests that for nearly $40 \%$ of the former group, parents did not recall having additional tests recommended for their child.

The two parental groups differed on two psychosocial concerns related to a genetics evaluation that might be brought out as a result of learning more about their child's deafness. Parents who took their child for genetics evaluation were more likely to have been concerned that an evaluation would not make them feel better $(P=0.02)$ and that they would learn information that would make them feel uncomfortable $(P=0.06)$ compared with those who did not take their child to genetics evaluation. Nearly all children were covered by health insurance; however, parents who did not take their child to a genetics evaluation were nonsignificantly more likely to indicate that they were unsure whether the insurance covered the visit compared with those who took their child for a genetics evaluation $(P=0.13)$.

Ethnic heritage was the only demographic, audiologic, or genetic index associated with parents' response regarding genetics evaluation, where parents of Hispanic or Asian heritage were more likely to take their child for evaluation compared with parents of white heritage $(P=0.04)$. To further examine whether the Hispanic and Asian children were more likely to have had a genetics evaluation because their GJB2/GJB6 result was normal, we constructed a three-way table of ethnic heritage, GJB2/GJB6 result, and whether or not a child had a genetics evaluation for qualitative analysis because the sample is too small to perform a valid statistical analysis. Although the table reconfirms that more Hispanic $(66.7 \%)$ and Asian (100\%) children than white $(25 \%)$ children in our sample had a genetics evaluation, it also illustrates that GJB2/GJB6 results were less likely to explain the child's deafness in the white and Hispanic families $(75 \%, 100 \%)$ compared with the Asian families $(50 \%)$ in the sample. Furthermore, although $100 \%$ of white and His-

Table 2 Description of study sample and comparison with sample from which participants were recruited

\begin{tabular}{|c|c|c|c|}
\hline Descriptor & Current study & GHL study & $P$ \\
\hline Number of parents (number of couples) & $30(6)$ & $158(59)$ & - \\
\hline Number of families & 24 & 99 & - \\
\hline$\%$ Female_parents & $73 \%$ & $62 \%$ & 0.30 \\
\hline \multicolumn{4}{|l|}{ Ethnicity/race-parents } \\
\hline White & $50 \%$ & $38.0 \%$ & 0.77 \\
\hline Hispanic & $33.3 \%$ & $41.8 \%$ & \\
\hline Asian & $16.7 \%$ & $16.5 \%$ & \\
\hline African American & $0 \%$ & $1.9 \%$ & \\
\hline Hawaiian/Other Pacific Islander & $0 \%$ & $1.9 \%$ & \\
\hline Average age at GHL enrollment—parents (SD) & $33.2(5.60)$ & $32.7(6.4)$ & 0.70 \\
\hline Median family income-parents & $\$ 95 \mathrm{~K}$ & $\$ 35 \mathrm{~K}-\$ 50 \mathrm{~K}$ & 0.15 \\
\hline Median education-parents & $4 \mathrm{yr}$ of college & $2-4 \mathrm{yr}$ of college & 0.72 \\
\hline$\%$ deaf or hard of hearing — parents & $3.3 \%$ & $5.7 \%$ & 1.0 \\
\hline Average age at GHL enrollment—children (SD) & 12.4 mo $(11.1)$ & $13.6 \mathrm{mo}(11.1)$ & 0.62 \\
\hline$\%$ Children with GJB2/GJB6-related deafness & $25 \%$ & $23.2 \%$ & 1.0 \\
\hline
\end{tabular}


panic parents who took their child for a genetics evaluation received a negative $G J B 2 / G J B 6$ result, $50 \%$ of the Asian parents received a positive $G J B 2 / G J B 6$ result. Hence, there is no strong evidence for an interaction between ethnic heritage, GJB2/GJB6 result, and whether or not a child had a genetics evaluation.

Parents' comments to the open-ended question revealed that the most common reason for taking their child to a genetics clinic was because the child had multiple malformations or medical issues ( $n=3$ children). In contrast, none of the parents in the other group indicated that their child had multiple malformations; instead the most common reason for not taking their child to a genetics clinic was that learning the etiology of their child's deafness was not perceived as important (e.g., "Doesn't really matter to us and is not a concern enough to warrant further investigation," "Our purpose/goal is to love our little guy with all our hearts, and we didn't see how exploring the reasons why this may have happened would be important or matter to us"). To further examine whether parents of Hispanic or Asian heritage were more likely to have taken their child for a genetics evaluation because of multiple anomalies, we performed a three-way analysis evaluating ethnic heritage, comments about multiple anomalies, and whether or not child had a genetics evaluation, recognizing that the sample is too small to perform a valid statistical analysis. Although there seems to be an association between ethnic heritage and anomalies in our sample $(8.3 \%, 16.7 \%, 25 \%, 0 \%$ white, Hispanic, Asian, and mixed heritage children, respectively), this phenomenon does not seem to explain the relationship between ethnic heritage and whether or not a child had a genetics evaluation as $33 \%, 25 \%$, and $25 \%$ of white, Hispanic, and Asian children who had a genetics evaluation also had a parental comment about multiple anomalies as the reason for taking their child for the evaluation.

\section{DISCUSSION}

Despite recommendations for genetics evaluation and counseling for all children with confirmed deafness, ${ }^{14}$ a significant percentage of children do not undergo evaluation. ${ }^{22}$ The purpose of this study was to identify factors that are associated with why some parents pursue genetics evaluation for their deaf or hard-of-hearing child and others do not. The participants of the UCLA GHL study serve as a model for the increasingly common scenario of parents whose children receive genetic testing for deafness outside of a standard clinical genetic setting, followed by a recommendation for a clinical genetics evaluation and counseling.

The findings from our study suggest that compared with parents who did not take their child for a genetics evaluation, those who did were more likely to (1) have supportive pediatricians, (2) feel it was important or would be helpful to their child, (3) recall the recommendation for a genetics evaluation, (4) have family members who wanted the child to have an evaluation, and (5) have Asian or Hispanic background. In addition, qualitative data suggest that parents who took their child for a genetics evaluation were more likely to report that their child has multiple anomalies. Although the survey response rate was low, the study sample was found to be representative of the larger GHL sample from which it was drawn on a variety of demographic, audiologic, and genetic indices, thereby increasing the credibility of these findings.

The importance of parental perceptions and pediatrician support in facilitating genetics evaluation for deaf children was recently reported, ${ }^{27}$ and our results suggest that this is a robust finding that should be considered when developing strategies to increase uptake of genetics evaluations for deaf children. Although not previously reported, it is not surprising that parents of children with multiple malformations are more likely to seek genetics evaluation as clinical genetics has traditionally evaluated children with anomalies. However, the recommendation for genetics evaluation of deaf children is not limited to those with multiple anomalies, and perhaps greater awareness of the utility of genetics evaluation for apparently nonsyndromic deaf children is needed.

Ethnic differences in parental perceptions of genetic testing for deafness have been observed previously, ${ }^{35}$ where parents of Asian or Hispanic background were more likely than white parents to view genetic testing in terms of helping with their child's medical care. In this study, we observed a similar phenomenon in which parents of Asian or Hispanic background were more likely than white parents to take their child for a genetics evaluation. Further examinations revealed that the ethnic differences were not explained by differences in frequencies of multiple anomalies or $G J B 2 / G J B 6$ result, suggesting instead that ethnocultural differences may play a role in views about medicogenetic information. Similarly, the social and family context has been shown to influence decisions regarding prenatal and presymptomatic genetic testing, ${ }^{38,39}$ and this study extends these findings to suggest that the family also plays some role in influencing parents' decisions regarding genetics evaluation for deafness.

Parents in this sample had a generally good understanding of what takes place during a genetics evaluation and their level of understanding was not substantively associated with their decisions to take their child for genetics evaluation. The two parental groups also did not substantively differ on potential psychosocial aspects associated with a genetics evaluation, nor did they have concerns about possible language barriers, suggesting that components of genetic counseling such as communication, risk assessment, and handling potentially uncomfortable information, neither facilitate nor hinder decisions about genetics evaluation for their child. Finally, structural factors such as access to a genetics clinic, a reliable method of transportation, or presence of health insurance were not problematic for parents in this sample and were not significantly associated with parental decision regarding genetics evaluation. Although the two parental groups differed weakly in terms of whether or not the health insurance would cover a visit to a genetics clinic, this difference seems to be explained by a lack of investigation on the part of those who did not take their child for a genetics evaluation rather than denial by the health insurance company.

This study has several limitations and so generalizing our findings should be done with caution. First, this is a very small study, with a relatively low-response rate. Although the current study sample is representative of the larger group from which it was drawn, the small sample size yields limited power to identity additional variables associated with whether or not parents take their child to a genetics clinic. Second, although ethnically diverse, the socioeconomic and educational status of the participants was generally high, and this may explain why logistical factors and language did not seem to be particular impediments to attending the genetics clinic. Additional studies with larger and more socioeconomically diverse samples may help to further illuminate barriers to, and facilitators of, genetics evaluation. Third, it is important to bear in mind that all of the parents in this study were able to participate in a larger study on genetic testing and were counseled by a genetic counselor regarding the importance of genetics evaluation. 
Algorithms have been proposed that recommend GJB2 testing as the first step in the evaluation of an apparently nonsyndromic deaf/hard-of-hearing child because a positive result eliminates the need for other medical tests. ${ }^{14,40}$ It is currently unclear whether GJB2 testing, along with pre- and posttest counseling, primarily will take place within or outside of a genetics clinic. However, it seems likely that nongenetics professionals such as pediatricians, otolaryngologists, and audiologists will play a large role in first-tier genetic testing because of the limited number of genetics professionals and the fact that parents of a deaf/hard-of-hearing child will have early and repeated contact with these health care professionals. When genetic testing takes place outside of a genetics clinic, it would seem logical that parents who receive a positive GJB2 result would remain within their primary care setting, whereas those who receive a negative or inconclusive result would be referred for a genetics evaluation. A potential advantage of this step in the evaluation algorithm is that it would focus the limited genetics workforce on children with possibly less straightforward etiologies of their deafness, including syndromic forms of deafness, where clinical and family history data may be required to determine the best course of action. However, genetic testing is different from other routine testing and raises a number of complex issues including the technicalities of genetic testing, the language of genetics, the relevance to other family members, and reproductive issues. ${ }^{14,22}$ For this triage step to be successful, nongenetics professionals need to understand and convey the complexities and subtleties of genetic information. However, recent studies raise concerns about nongeneticists' understanding of genetic information (positive and negative results) and their implications, ${ }^{22,41}$ illustrating a current limitation to this step in the algorithm. Possible solutions to this limitation include increasing the level of understanding of genetic information among nongenetics professionals and including genetic counselors within these nontraditional genetics settings, as has happened in other nontraditional genetics settings such as oncology. Given current limitations, empirical data are needed to determine whether the potential advantages of focusing genetics referrals only on deaf/hard-of-hearing children with non-GJB2 etiologies outweigh the potential benefits of genetics referral for all parents of a deaf/hard-of-hearing child regardless of $G J B 2$ results. Interestingly, in the current sample, the ability of prior $G J B 2 / G J B 6$ testing to explain their child's deafness did not seem to play a role in subsequent parental decision about genetics evaluation. This result provides empirical evidence that genetics evaluation can be perceived as important to parents regardless of the genetic test result and that genetics clinics should expect to counsel some parents whose children have received a genetic explanation for the deafness outside of traditional genetics clinics.

In closing, the importance of the pediatrician regarding genetics evaluation for deaf children has now been observed in two studies. Although referral is an important factor in facilitating genetics evaluation, the overall pediatrician referral rate seems to be low ( 4 of 24 families [ $\sim 17 \%$ ] received a referral in the current study; $24 \%$ in Powell and Roche. ${ }^{27}$ ), and one contributing factor may be poor understanding of the benefits and purposes of genetic evaluations or the inability to adequately convey this information to parents. ${ }^{27}$ Our study suggests that efforts to educate pediatricians about the role of genetics evaluation for deaf children may be essential to ensure appropriate care for deaf or hard-of-hearing children as recommended by the American College of Medical Genetics.

\section{ACKNOWLEDGMENTS}

This work was supported in part by funding from the National Institutes on Deafness and other Communication Disorders (R01 DC0055663) and from the National Human Genome Research Institute (R01 HG003871). The authors thank Janet Sinsheimer, $\mathrm{PhD}$, for statistical assistance and the families that participated in this research.

\section{REFERENCES}

1. Morton ND. Genetic epidemiology of hearing impairments. Ann N Y Acad Sci 1991;630:16-31

2. Gorlin RJ, Toriello HV, Cohen MM Jr. Hereditary hearing loss and its syndromes. New York: Oxford University Press, 1995.

3. Nance WE. The genetics of deafness. Ment Retard Dev Disabil Res Rev 2003;9:109-119.

4. Rehm HL. A genetic approach to the child with sensorineural hearing loss. Semin Perinatol 2005;29:173-181.

5. Denoyelle F, Weil D, Maw MA, et al. Prelingual deafness: high prevalence of a 30delG mutation in the connexin 26 gene. Hum Mol Genet 1997;6: 2173-2177.

6. Estivill X, Fortina P, Surrey S, et al. Connexin-26 mutations in sporadic and inherited sensorineural deafness. Lancet 1998;351:394-398.

7. Kelsell DP, Dunlop J, Stevens HP, et al. Connexin 26 mutations in hereditary non-syndromic sensorineural deafness. Nat 1997;387:80-83.

8. del Castillo I, Villamar M, Moreno-Pelayo MS, et al. A deletion involving the connexin 30 gene in nonsyndromic hearing impairment. $N$ Engl J Med 2002;346:243-249.

9. Green GE, Scott DA, McDonald JM, Woodworth GG, Sheffield VC, Smith RJ. Carrier rates in the midwestern United States for GJB2 mutations causing inherited deafness. JAMA 1999;281:2211-2216.

10. Kenneson A, Van Naarden Braun K, Boyle C. GJB2 (connexin 26) variants and nonsyndromic sensorineural hearing loss: a HuGE review. Genet Med 2002; $4: 258-274$

11. del Castillo I, Moreno-Pelayo MA, del Castillo FJ, et al. Prevalence and evolutionary origins of the del(GJB6-D13S1830) mutation in the DFNB1 locus in hearing-impaired subjects: a multicenter study. Am J Hum Genet 2003;73:1452-1458.

12. Joint Committee on Infant Hearing. Year 2000 position statement. Audiol Today 2000;3:23.

13. Yoshinaga-Itano C, Sedey AL, Coulter DK, Mehl AL. Language of earlyand later-identified children with hearing loss. Pediatrics 1998;102:11611171 .

14. American College of Medical Genetics. Genetics evaluation guidelines for the etiologic diagnosis of congenital hearing loss. Genet Med 2002;4:162 171

15. Joint Committee on Infant Hearing. Position statement: principles and guidelines for early hearing detection and intervention programs. Pediatrics 2000;106:798-817.

16. Joint Commission on Infant Hearing. Year 2007 position statement: principles and guidelines for early hearing detection and intervention programs. Pediatrics 2007;120:898-921.

17. Morton CC, Nance WE. Newborn hearing screening-a silent revolution. $N$ Engl J Med 2006;354:2151-2164.

18. Kennedy C, McCann D. Universal neonatal hearing screening moving from evidence to practice. Arch Dis Child Fetal Neonatal Ed 2004;89:F378F383.

19. de Swanepoel W, Louw B, Hugo R. A novel service delivery model for infant hearing screening in developing countries. Int J Audiol 2007;46:321327.

20. White KR. Early hearing detection and intervention programs: opportunities for genetic services. Am J Med Genet 2004;130A:29-36.

21. Burton SK, Blanton SH, Culpepper B, et al. Education in the genetics of hearing loss: a survey of early hearing detection and intervention programs. Genet Med 2006;8:510-517.

22. Duncan RD, Prucka S, Wiatrak BJ, Smith RJH, Robin NH. Pediatric otolaryngologists' use of genetic testing. Arch Otolaryngol Head Neck Surg 2007;133:231-236

23. Pandya A, Arnos KS, Xia XJ, et al. Frequency and distribution of GJB2 (connexin 26) and GJB6 (connexin 30) mutations in a large North American repository of deaf probands. Genet Med 2003;5:295-303.

24. Schimmenti LA, Martinez A, Fox M, et al Genetic testing as part of the early hearing detection and intervention (EHDI) process. Genet Med 2004; 6:521-525

25. Withrow KA, Burton S, Arnos KA, Kalfoglou A, Pandya A. Consumer motivations for pursuing genetic testing and their preferences for the provision of genetic services for hearing loss. J Genet Counsel 2008;17:252260.

26. Brunger JW, Murray GS, O'Riordan M, Matthews AL, Smith RJH, Robin 
NH. Parental attitudes toward genetic testing for pediatric deafness. Am J Hum Genet 2000;67:1621-1625.

27. Powell CM, Roche MI. A survey assessing parental attitudes and genetic services for early-onset hearing loss. Paper presented at: 15th Annual Clinical Genetics Meeting of the American College of Medical Genetics, Phoenix, Arizona, 2008.

28. Esser-Stuart JE, Lyons MA. Barriers and influences in seeking health care among lower income minority women. Soc Work Health Care 2002;35:85-99.

29. Jacobs EA, Chen AHM, Karliner LS, Agger-Gupta N, Mutha S. The need for more research on language barriers in health care: a proposed research agenda. Milbank $Q$ 2006;84:111-133.

30. Case DO, Andrews JE, Johnson JD, Allard SL. Avoiding versus seeking: the relationship of information seeking to avoidance, blunting, coping, dissonance, and related concepts. J Med Libr Assoc 2005;93:353-362.

31. Shaw C, Abrams K, Marteau TM. Psychological impact of predicting individuals' risks of illness: a systematic review. Soc Sci Med 1999;49: 1571-1598.

32. Godard B, Pratte A, Dumont M, Simard-Lebrun A, Simard J. Factors associated with an individual's decision to withdraw from genetic testing for breast and ovarian cancer susceptibility: implications for counseling. Genet Test 2007;11:45-54.

33. Steinberg AG, Kaimal G, Bain L, Krantz I, Li Y. Parental narratives on genetic testing for children with hearing loss: a qualitative inquiry. Am J Med Genet A 2007; 143:1533-1545.

34. Palmer CGS, Martinez A, Fox M, et al. Genetic testing and the early hearing detection and intervention process. Volta Rev 2003;103:371-390.

35. Palmer CGS, Martinez A, Fox M, Sininger Y, Grody WW, Schimmenti LA. Ethnic differences in parental perceptions of genetic testing for deaf infants. $J$ Genet Counsel 2008;17:129-138.

36. Schimmenti LA, Martinez A, Teletar M, et al. Infant hearing loss and connexin testing in a diverse population. Genet Med 2008; 10:517-524.

37. Brislin RW. Back-translation for cross-cultural research. J Cross Cult Psychol 1970;1:185-216.

38. Learman LA, Kuppermann M, Gates E, Nease RF Jr, Gildengorin V, Washington AE. Social and familial context of prenatal genetic testing decisions: are there racial/ethnic differences? Am J Med Genet C (Semin Med Genet) 2003;119C:19-26.

39. Biesecker BB, Ishibe N, Hadley DW, et al. Psychosocial factors predicting BRCA1/BRCA2 testing decisions in members of hereditary breast and ovarian cancer families. Am J Med Genet 2000;93:257-263.

40. Greinwald JH Jr, Hartnick CJ. The evaluation of children with sensorineural hearing loss. Arch Otolaryngol Head Neck Surg 2002;128:84-87.

41. Robin NH, Dietz C, Arnold JE, Smith RJH. Pediatric otolaryngologists' knowledge and understanding of genetic testing for deafness. Arch Otolaryngol Head Neck Surg 2001;127:937-940. 